\title{
REFLEXÕES SOBRE A SELEÇÃO DE INDICADORES SOCIAIS E AMBIENTAIS NA POLÍTICA NACIONAL DE PROTEÇÃO E DEFESA CIVIL EM ÂMBITO LOCAL
}

\author{
THOUGHTS ON THE SELECTION OF SOCIAL AND \\ ENVIRONMENTAL INDICATORS BY THE NATIONAL POLICY \\ FOR LOCAL PROTECTION AND CIVIL DEFENSE
}

\author{
Alexander Josef Sá Tobias da Costa \\ Doutor em Ambiente e Sociedade - NEPAM / UNICAMP \\ Professor Adjunto do Depto. de Geografia Física do IGEOG - UERJ \\ e-mail: ajcostageo@gmail.com \\ Rodrigo Silva da Conceição \\ Doutorando em Meio Ambiente - PPG-MA / UERJ \\ Professor Substituto do Depto. de Geografia Física do IGEOG - UERJ \\ e-mail: rsc_geo@yahoo.com.br
}

\begin{abstract}
RESUMO
Neste ensaio teórico, os autores defendem a utilização de indicadores atrelados ao diagnóstico socioambiental na aplicação, em âmbito local, dos instrumentos e diretrizes previstos na Política Nacional de Proteção e Defesa Civil, recentemente instituída, no que se refere, primordialmente, ao(re)conhecimento de uma área (e de seus processos e fenômenos naturais e sociais). Foram consultadas a referida política e suas diretrizes, principalmente no que se estabelece como competência dos municípios; paralelamente, foram revistos o conceito de indicador e os elementos para sua seleção e utilização. Por fim, foram sugeridos indicadores em potencial, agrupados nas dimensões ambiental, sociodemográfica e institucional, a partir de consulta a publicações de órgãos competentes ao levantamento e disseminação de informações como o Instituto Brasileiro de Geografia e Estatística (em nível nacional) e o Instituto Pereira Passos, vinculado ao município do Rio de Janeiro (em nível local, de maneira exemplificativa). A efetiva aplicação e integração deste conjunto de ferramentas podem contribuir ao direcionamento e definição de ações, de cunho preventivo e corretivo, associadas à gestão de riscos de desastres.
\end{abstract}

Palavras-chave: Indicadores sociais e ambientais, Gestão local, Política Nacional de Proteção e Defesa Civil.

Geo UERJ - Ano 14, nº. 23, v. 2, $2^{\circ}$ semestre de 2012 p. 413-436

ISSN: 1415-7543 E-ISSN: 1981-9021

http://www.e-publicacoes.uerj.br/index.php/geouerj 


\begin{abstract}
In this theoretical essay, the authors advocate the use of indicators tied to environmental diagnosis in the application, locally, of the instruments and guidelines contained in the National Policy of Protection and Civil Defense, which were recently established, regarding, primarily, to the (re)cognition of an area (and its processes and natural and social phenomena). Were consulted the mentioned policy and its guidelines, specially what is considered as competence of municipalities; in parallel, were reviewed the concept of indicator and the elements for its selection and use. Finally, were suggested potential indicators, grouped in the environmental, sociodemographic and institutional dimensions, based on consultation to publications of public organizations competent for the collection and dissemination of information as the Brazilian Institute of Geography and Statistics (nationally) and the Pereira Passos Institute, linked to the municipality of Rio de Janeiro (at the local level, as an example). The effective application and integration of this toolkit can contribute to the direction and defining of actions, with preventive and corrective features, related to disaster risk management.
\end{abstract}

Key Words: Social and environmental indicators, Local management, National Policy of Protection and Civil Defense.

\title{
INTRODUÇÃO E OBJETIVOS
}

Quando se pensa em política pública têm-se a noção de um aparato legal, voltado à orientação das ações de gestão. A política pode ser entendida como um conjunto de diretrizes, estabelecido a partir de normas e princípios gerais, definida por lei, com o objetivo de equacionar ou resolver problemas da coletividade (BREDARIOL e VIEIRA, 1998).

No Brasil, após a ocorrência de grandes desastres ambientais, principalmente os relativos aos processos de encostas e hidrológicos, os quais assolam a população que se encontra em grande parte em manchas urbanas, percebe-se o crescimento de importância do conceito de risco ambiental na pauta de políticas públicas. É neste contexto que foi implementada, em abril de 2012, a Política Nacional de Proteção e Defesa Civil - PNPDEC.

Essa política é uma clara resposta aos problemas sociais e ambientais, atualmente alardeados pela mídia, que se impõem frente ao modelo histórico de apropriação e uso do solo inadequado em áreas ambientalmente frágeis. Destaca-se

Geo UERJ - Ano 14, nº. 23, v. 2, $2^{\circ}$ semestre de 2012 p. 413-436

ISSN: 1415-7543 E-ISSN: 1981-9021

http://www.e-publicacoes.uerj.br/index.php/geouerj 
ainda, neste cenário, a resposta à necessidade de um modelo específico para a gestão de riscos, revelando ações preventivas e corretivas associadas, inclusive, e como não poderia deixar de ser, a outros níveis de gestão (urbano, ambiental, etc.).

O conceito de gestão refere-se, primordialmente, aos procedimentos operacionais (em um sentido prático), à administração e à aplicação de leis e seus regulamentos, normas, planos (e programas vinculados), bem como à utilização de indicadores que reflitam distintos aspectos da realidade (SOUZA, 2002).

Neste sentido, a pesquisa científica pode e deve contribuir para o planejamento e gestão territorial, no qual se insere a temática do risco de desastres, ou mais amplamente, risco ambiental. Tal iniciativa se revela na participação da produção científica relacionada à modelagem e manipulação de ferramentas de informação, ao diagnóstico socioambiental, à avaliação de impactos, às análises integradas, entre outros que envolvam o (re)conhecimento de uma dada realidade espacial.

No meio científico e governamental vem se estabelecendo a utilização de indicadores como um recurso metodológico para a mensuração de dados qualitativos e/ou quantitativos e organização das informações frente a objetivos específicos, revelando cenários em variadas dimensões (social, ambiental, econômica, política, etc.).

O presente artigo busca introduzir a temática dos indicadores, sob a perspectiva de sistematização em variadas dimensões e da seleção dos mesmos. A partir daí, objetiva-se, além de sua contribuição com enfoque ao diagnóstico socioambiental e (re)conhecimento da realidade em escala local, subsidiar o planejamento e a gestão territorial de riscos orientados no decorrer da implementação da PNPDEC e do desenvolvimento de futuros planos associados em escala nacional e, principalmente, local.

\section{INDICADORES: BREVE REVISÃO TEÓRICA}

O termo indicador provém do latim "indicare", que significa descobrir, apontar, anunciar, estimar. Em uma concepção científica, indicadores, em termos gerais, são "ferramentas constituídas por uma ou mais variáveis que, associadas, através de

Geo UERJ - Ano 14, nº. 23, v. 2, $2^{\circ}$ semestre de 2012 p. 413-436

ISSN: 1415-7543 E-ISSN: 1981-9021

http://www.e-publicacoes.uerj.br/index.php/geouerj 
diversas formas, revelam significados mais amplos sobre os fenômenos a que se referem" (IBGE, 2012).

Conforme Bellen (2007) avalia, dentre algumas visões, os indicadores podem comunicar ou informar sobre o progresso em direção a uma determinada meta (indicadores de sustentabilidade), assim como podem demonstrar de maneira mais perceptível uma tendência ou fenômeno que não seja imediatamente detectável.

Ainda com base nesta referência, pode-se dizer que o objetivo dos indicadores é "agregar e quantificar informações de modo que sua significância fique mais aparente. Eles simplificam as informações sobre fenômenos complexos tentando melhorar com isso o processo de comunicação" (BELLEN, op. cit., p. 42).

Indicadores podem ser classificados como qualitativos ou quantitativos. Segundo Jannuzzi (2001, p. 20), os indicadores quantitativos, ou objetivos, "se referem a ocorrências concretas ou entes empíricos da realidade social, construídos a partir das estatísticas públicas disponíveis". Tais estatísticas podem estar relacionadas ao censo, por exemplo.

Pela sua maior precisão, os métodos quantitativos para a construção de indicadores têm sido preferidos aos qualitativos. Entretanto, indicadores qualitativos e quantitativos, embora ainda insipientes, podem ser integrados em análises integradas multidimensionais (BOLLMANN, 2009).

Segundo Tunstall (1994, apud BELLEN, 2007), as principais funções dos indicadores são: avaliação de condições e tendências; comparação entre lugares e situações; avaliação de condições e tendências em relação às metas e aos objetivos; prover informações de advertência e antecipar futuras condições e tendências. Contribuindo a esta visão, pode-se ainda destacar, como uma função específica dos indicadores, a integração entre dados qualitativos do meio físico natural e dados quantitativos sociodemográficos para análises complexas de condições e tendências.

A seleção e construção de indicadores seguem alguns critérios básicos quanto à sua adoção, relacionados à sua estrutura, justificativa e balizamento (Quadro 1). Na realidade, tais critérios podem ser considerados mais como um parâmetro inicial, já que os mesmos serão sempre (re)definidos em função dos objetivos.

Geo UERJ - Ano 14, no. 23, v. 2, $2^{\circ}$ semestre de 2012 p. 413-436

ISSN: 1415-7543 E-ISSN: 1981-9021

http://www.e-publicacoes.uerj.br/index.php/geouerj 
Quadro 1 - Critérios para a seleção de indicadores.

\begin{tabular}{|c|l|}
\hline CRITÉRIO & \multicolumn{1}{|c|}{ CARACTERÍSTICAS } \\
\hline FÁCIL COMPREENSÃo & $\begin{array}{l}\text { Devem: permitir interpretações e percepções semelhantes } \\
\text { por parte de todos os usuários; ser transparentes, isto é, de } \\
\text { fácil compreensão para usuários com distintos graus de } \\
\text { compreensão e informação. }\end{array}$ \\
\hline CONFIABILIDADE & $\begin{array}{l}\text { Devem: ter credibilidade técnico-científica e ter origem em } \\
\text { instituições de reconhecida capacidade e confiabilidade } \\
\text { técnicas. }\end{array}$ \\
\hline TRANSVERSALIDADE/UNIVE & $\begin{array}{l}\text { Devem: poder ser utilizados para conhecer as tendências de } \\
\text { diferentes fenômenos, e, ao mesmo tempo, permitir fazer } \\
\text { comparações entre diversas realidades locais. }\end{array}$ \\
\hline DISPONIBILIDIDADE & $\begin{array}{l}\text { Devem: estar disponíveis e apresentar, de preferência, } \\
\text { séries históricas na escala territorial de análise, o qual } \\
\text { permite compreender o comportamento do fenômeno no } \\
\text { tempo. }\end{array}$ \\
\hline
\end{tabular}

Fonte: Adaptado de Consórcio Parceria 21 (2002).

Além destes critérios, Jannuzzi (2001) agrega outros (Quadro 2), ao definir propriedades desejáveis na definição e seleção de indicadores. Retomando a visão do autor, o indicador deve ter um grau de cobertura adequado aos objetivos a que se presta, devendo ainda, ser sensível, reprodutível, comunicável, atualizável periodicamente, ser amplamente desagregável em termos geográficos, sociodemográficos e socioeconômicos e gozar de certa historicidade.

Quadro 2 - Propriedades desejáveis para a seleção de indicadores.

\begin{tabular}{|c|l|}
\hline PROPRIEDADE & \multicolumn{1}{|c|}{ CARACTERísTICAS } \\
\hline RELEVÂNCIA & $\begin{array}{l}\text { Relacionada à pertinência da produção e uso do indicador a } \\
\text { partir de uma agenda de discussões. }\end{array}$ \\
\hline VALIDADE & $\begin{array}{l}\text { Corresponde ao grau de proximidade entre o conceito e a } \\
\text { medida, refletindo, de fato, o conceito ao que o indicador se } \\
\text { propõe. }\end{array}$ \\
\hline CONFIABILIDADE & $\begin{array}{l}\text { Relacionada à qualidade do levantamento dos dados usados } \\
\text { no cômputo do indicador. }\end{array}$ \\
\hline COBERTURA & $\begin{array}{l}\text { Corresponde a cobertura espacial e ao potencial de } \\
\text { representação da realidade empírica em análise. }\end{array}$ \\
\hline SENSIBILIDADE & $\begin{array}{l}\text { Diz respeito à capacidade do indicador em refletir } \\
\text { mudanças significativas de acordo com a realidade. }\end{array}$ \\
\hline INTELIGIBILIDADE & $\begin{array}{l}\text { Diz respeito à transparência da metodologia de construção } \\
\text { do indicador. }\end{array}$ \\
\hline COMUNICABILIDADE & Diz respeito à facilidade de compreensão do indicador. \\
\hline FACTIBILIDADE & Relacionada à possibilidade de obtenção dos dados e \\
\hline
\end{tabular}
Geo UERJ - Ano 14, nº. 23, v. 2, $2^{\circ}$ semestre de 2012 p. 413-436

ISSN: 1415-7543 E-ISSN: 1981-9021 


\begin{tabular}{|c|l|}
\hline & mensuração dos mesmos. \\
\hline PERIODICIDADE & Relacionada à possibilidade de atualização do indicador. \\
\hline DESAGREGABILIDADE & $\begin{array}{l}\text { Relacionada à construção de indicadores referidos a espaços } \\
\text { geográficos reduzidos e grupos específicos (grupos } \\
\text { vulneráveis, por exemplo). }\end{array}$ \\
\hline HISTORICIDADE & $\begin{array}{l}\text { Relacionada à propriedade de se dispor de séries históricas } \\
\text { extensas e comparáveis do indicador. }\end{array}$ \\
\hline
\end{tabular}

Fonte: Adaptado de Jannuzzi (2001).

Deus (2000) resumiu alguns critérios adotados em trabalhos desenvolvidos com este enfoque. A autora propõe três grupos básicos (Quadro 3), discutindo a importância da consideração destes no processo de seleção, elaboração e uso dos indicadores.

Quadro 3 - Síntese dos critérios para a seleção de indicadores.

\begin{tabular}{|c|l|}
\hline GRUPOS BÁSICOS & \multicolumn{1}{|c|}{ CARACTERÍSTICAS } \\
\hline $\begin{array}{c}\text { CONFIABILIDADE DOS } \\
\text { DADOS }\end{array}$ & $\begin{array}{l}\text { Viabilidade científica e medição, disponibilidade, } \\
\text { qualidade, custo-eficiência de obtenção, séries temporais e } \\
\text { acessibilidade. }\end{array}$ \\
\hline $\begin{array}{c}\text { RELAÇÃO COM OS } \\
\text { PROBLEMAS E PRIORIDADES }\end{array}$ & $\begin{array}{l}\text { Representatividade e conveniência de escalas, cobertura } \\
\text { geográfica, sensibilidade às mudanças, especificidade e } \\
\text { conexão. }\end{array}$ \\
\hline $\begin{array}{c}\text { UTILIDADE PARA O } \\
\text { USUÁRIO }\end{array}$ & $\begin{array}{l}\text { Aplicabilidade e não redundância, compreensibilidade, } \\
\text { interpretabilidade, valor de referência e comparabilidade. }\end{array}$ \\
\hline
\end{tabular}

Fonte: Adaptado de Deus (2000).

Frequentemente, os indicadores são apresentados na forma de índices, objetivando a simplificação da apresentação dos dados, e agregando os valores dos indicadores individuais em um único valor de índice. Ou seja, o índice é uma agregação de indicadores, ou um indicador com elevado grau de agregação.

Batata (2004) entende que os índices correspondem a um grupo específico de indicadores, formulados a partir da combinação algébrica de diferentes indicadores, segundo uma determinada intenção. Esta combinação pode ser realizada a partir de cálculos matemáticos, ou mesmo, de álgebra de mapas (cruzamento de mapeamentos e processamento em meio computacional). Seu objetivo é buscar uma visão sintética e simplificada de um fenômeno ou um conjunto de fenômenos.

A complexidade metodológica na construção do indicador ou a quantidade de informação usada para sua definição é entendida por Jannuzzi (2001) como um critério

Geo UERJ - Ano 14, no. 23, v. 2, $2^{\circ}$ semestre de 2012 p. 413-436

ISSN: 1415-7543 E-ISSN: 1981-9021

http://www.e-publicacoes.uerj.br/index.php/geouerj 
de diferenciação entre indicadores simples ou compostos. O autor indica que os indicadores compostos, também chamados de sintéticos ou de índices, são elaborados mediante a aglutinação de dois ou mais indicadores simples, referidos a uma ou diferentes dimensões da realidade.

Dentre as vantagens na utilização dos índices, está a sua característica principal que é relacionada ao potencial de agregação. De maneira geral, os índices resumem temas complexos, quase que didaticamente. Uma desvantagem principal a ser apontada baseia-se no fato de que a seleção de indicadores e seus pesos, para a construção de um índice, podem ser questionáveis (MIBIELLI, 2009).

Adaptando a visão social de Jannuzzi (2001) para uma perspectiva mais geral, podemos dizer que, os indicadores são medidas dotadas de significado, utilizadas para substituir, quantificar ou operacionalizar um conceito abstrato de interesse teórico (para pesquisa acadêmica) ou programático (para formulação de políticas).

Para a pesquisa acadêmica, o indicador seria o elo entre os modelos explicativos (baseados em teorias sociais, físicas, etc.) e a evidência empírica dos fenômenos observados. Em uma perspectiva programática, o indicador atuaria como um instrumento operacional para o monitoramento da realidade, para fins de formulação e reformulação de políticas públicas.

Neste sentido, podemos avaliar que o objetivo define um indicador, porém podemos ainda avançar em uma visão integradora. Ou seja, os indicadores, em suas estruturas e tipos, podem estar correlacionados.

A partir da conceituação de indicador, e considerando suas mais variadas aplicações, podemos nos deparar com definições mais específicas, como as relacionadas aos indicadores ambientais, indicadores sociais, de desenvolvimento sustentável, etc. Apesar desta categorização, os indicadores são factíveis de cruzamento, dependendo do objetivo.

Jannuzzi (2001) disserta que os indicadores sociais estão relacionados a medidas relacionadas a um conceito social. Garcias (1991) apresenta indicador social como um procedimento estatístico com objetivo de quantificar o grau de bem-estar ou qualidade de vida de uma população. Os indicadores sociais podem se referir à totalidade da população ou a grupos sociodemográficos específicos, dependendo do interesse Geo UERJ - Ano 14, nº. 23, v. 2, $2^{\circ}$ semestre de 2012 p. 413-436

ISSN: 1415-7543 E-ISSN: 1981-9021

http://www.e-publicacoes.uerj.br/index.php/geouerj 
substantivo inicialmente idealizado, e expresso como taxas, proporções, médias, distribuição por classes, e por fim, em índices.

De acordo com Jannuzzi (2001, p. 114), “uma dimensão que vem se tornando cada vez mais relevante na avaliação objetiva e subjetiva da qualidade de vida urbana é a condição ambiental". Estas condições ambientais podem se referir, por exemplo, à existência de sistemas de tratamento de esgoto e lixo ou às alterações no uso do solo e interferências na qualidade ambiental dos recursos. Ou seja, estes indicadores dizem respeito à disponibilidade de recursos naturais, à forma de uso dos mesmos e aos resíduos gerados no seu consumo.

Indicadores ambientais correspondem a informações sintéticas sobre o estado do meio ambiente, as tendências de alterações deste estado e os impactos de intervenções ou políticas de ação, sendo úteis tanto à sociedade civil como aos dirigentes públicos (IPP, 2005).

Os indicadores sociais e ambientais podem estar relacionados e cruzados em um modelo de causas e efeitos. Segundo o Consórcio Parceria 21 (2002, p. 48) "cada um destes padrões de relacionamento das atividades humanas com o meio ambiente demanda um conjunto específico de indicadores capazes de expressar o tipo particular de relação definido por cada um destes padrões." Por essa razão, os indicadores podem ser organizados segundo cada modelo. Assim, em muitos casos, os indicadores mais integrados estarão relacionados aos conceitos de risco e vulnerabilidade, e às suas especificidades no que diz respeito à questão socioambiental.

Por fim, destaque-se que os indicadores podem funcionar como uma ponte entre dados complexos e informações interpretadas acessíveis à população em geral (IPP, 2005; IBGE, 2012).

\section{POLÍTICA NACIONAL DE PROTEÇÃO E DEFESA CIVIL}

A Política Nacional de Proteção e Defesa Civil - PNPDEC (Lei No: 12.608 de 10 de abril de 2012), recentemente instituída, define as competências da União, estados e municípios nas ações de prevenção, mitigação, preparação, resposta e recuperação voltadas à proteção e Defesa Civil (BRASIL, 2012).

Neste sentido, a PNPDEC prevê a atuação articulada entre as esferas de governo,

Geo UERJ - Ano 14, $\mathrm{n}^{\circ} .23$, v. 2, $2^{\circ}$ semestre de 2012 p. 413-436

ISSN: 1415-7543 E-ISSN: 1981-9021

http://www.e-publicacoes.uerj.br/index.php/geouerj 
e ainda com participação de entidades públicas e privadas e sociedade em geral, para a redução de desastres e apoio às comunidades atingidas, evidenciando assim diretrizes de cunho preventivo e corretivo. Porém, vale destacar a priorização das ações preventivas relacionadas à minimização de desastres.

Tal aparato jurídico dispõe sobre o Sistema Nacional de Proteção e Defesa Civil - SINPDEC, o qual terá como finalidade contribuir no planejamento, articulação e execução dos programas e projetos de defesa civil. Versa ainda, sobre as finalidades do Conselho Nacional de Proteção e Defesa Civil - CONPDEC e autoriza a criação de um sistema de informações de monitoramento de desastres, para o qual terá grande peso as iniciativas de geração, alimentação e disseminação de informações sobre o território.

O citado sistema deverá ser implementado em ambiente informatizado, atuando por meio de base de dados compartilhada entre os integrantes do SINPDEC visando ao oferecimento de informações atualizadas para prevenção, mitigação, alerta, resposta e recuperação em situações de desastre.

A PNPDEC constitui um avanço na gestão local de riscos. Suas medidas tornam os estados responsáveis, por exemplo, pela indicação e mapeamento das áreas de risco e pela realização de estudos para identificação de ameaças e vulnerabilidades no território de abrangência. Cabe ainda aos estados o apoio aos municípios no levantamento de áreas de risco e na elaboração dos planos de contingência.

Já aos municípios compete a vistoria de edificações e zonas de risco, promovendo, quando for o caso, a intervenção preventiva e a evacuação da população de áreas ou residências vulneráveis. Os municípios deverão ainda manter a população informada sobre áreas de risco e ocorrência de eventos extremos; promover a coleta, a distribuição e o controle de suprimentos em situações de desastre; e adotar solução de moradia temporária para as famílias atingidas.

Em âmbito federal deverá ser realizado o cadastro nacional de municípios em áreas suscetíveis à ocorrência de deslizamentos e inundações. As cidades que estiverem na lista deverão elaborar o denominado Plano Diretor, para redução de riscos de desastres.

Geo UERJ - Ano 14, nº. 23, v. 2, $2^{\circ}$ semestre de 2012 p. 413-436

ISSN: 1415-7543 E-ISSN: 1981-9021

http://www.e-publicacoes.uerj.br/index.php/geouerj 
O Plano Diretor é a principal lei do município que trata da organização e ocupação do seu território, previsto constitucionalmente e também através do Estatuto da Cidade (BRASIL, 2001).

De acordo com as diretrizes da PNPDEC, a prefeitura de um município cadastrado que ainda não era obrigado a elaborar o Plano Diretor, em conformidade com o Estatuto da Cidade', dispõe de um prazo de cinco anos para envio do projeto à Câmara Municipal. Já aqueles que já possuem o plano deverão adequá-lo às novas regras em sua próxima revisão.

São definidas algumas exigências para a elaboração do Plano Diretor dos municípios cadastrados, a saber: parâmetros de parcelamento e uso do solo; mapeamento de áreas de risco; medidas de drenagem urbana necessárias à prevenção e à redução de impactos de desastres; e diretrizes para a regularização fundiária de assentamentos urbanos irregulares. Além disso, os programas habitacionais deverão priorizar as comunidades atingidas e os moradores em áreas de risco.

Dentre as diretrizes da PNPDEC, e se seu referido sistema destaca-se a realização do planejamento com base em pesquisas e estudos sobre áreas de risco e incidência de desastres no território nacional. Tal diretriz agrega valor a participação científica no processo de continuidade e implementação da política frente a diversas realidades territoriais.

Outra interessante diretriz a ser seguida, no contexto do planejamento e gestão de riscos de maneira integrada, diz respeito à adoção da bacia hidrográfica como unidade de análise das ações de prevenção de desastres relacionados a corpos d'água, refletindo a preocupação com os limites físicos e de atuação de processos naturais e antropizados, de maneira integrada.

Pode-se dizer que a PNPDEC possui um grande potencial de articulação com diversas políticas transversais ao tema (gestão de riscos), devendo, como preconiza um de seus objetivos mais explícitos, integrar-se às políticas de ordenamento territorial, desenvolvimento urbano, meio ambiente, gestão de recursos hídricos, geologia, dentre outras. Tal prerrogativa determina a necessidade de um maior (re)conhecimento do território, não somente de seus processos isolados, mas sim das diferentes respostas

Geo UERJ - Ano 14, nº. 23, v. 2, $2^{\circ}$ semestre de 2012 p. 413-436

ISSN: 1415-7543 E-ISSN: 1981-9021

http://www.e-publicacoes.uerj.br/index.php/geouerj 
(políticas incidentes) frente a diversas realidades, que, em muitos casos, se complementam e se antagonizam.

\section{MATERIAIS E MÉTODOS}

Em um primeiro momento, buscou-se identificar os objetivos e as diretrizes da PNPDEC, principalmente no que se estabelece como competência dos municípios, ou seja, do que se orienta com relação à gestão de riscos em escala local.

Paralelamente, e enfocando o potencial de contribuição ao desenvolvimento de diagnósticos a serem contemplados nos planos diretores, foram revistos o conceito de indicador, suas classificações e critérios para seleção dos mesmos. Além deste embasamento teórico buscou-se apresentar questões de ordem prática quanto à aplicação dos indicadores, a partir de experiências no contexto brasileiro de pesquisa e disseminação de informações.

Em um segundo momento, foram elencados indicadores em potencial ao diagnóstico socioambiental em âmbito local para a gestão de riscos, agrupados nas dimensões social, ambiental e institucional a partir de consulta a publicações de órgãos competentes ao levantamento e disseminação de informações como o Instituto Brasileiro de Geografia e Estatística - IBGE (em nível nacional) e o Instituto Pereira Passos - IPP, vinculado ao município do Rio de Janeiro (em nível local, de maneira exemplificativa).

Tais publicações se referem aos Indicadores de Desenvolvimento Sustentável (IBGE, 2012), periodicamente atualizada (a cada dois anos), e aos Indicadores Ambientais da Cidade do Rio de Janeiro (IPP, 2005).

Os indicadores do IBGE e do IPP foram agrupados segundo a similaridade de seus objetivos de representação, de acordo com as dimensões ambiental, sociodemográfica e institucional. Entre os indicadores ambientais houve, ainda, uma subdivisão entre indicadores ligados aos serviços de infraestrutura e aqueles que retratam questões relativas ao uso do solo.

\section{A CONTRIBUIÇÃO DE INDICADORES PARA A GESTÃO LOCAL DE RISCOS: UMA ŞELEÇÃO EXEMPLIFICATIVA}

Geo UERJ - Ano 14, nº. 23, v. 2, $2^{\circ}$ semestre de 2012 p. 413-436

ISSN: 1415-7543 E-ISSN: 1981-9021

http://www.e-publicacoes.uerj.br/index.php/geouerj 
Os indicadores selecionados refletem vínculos diretos à temática da PNPDEC e estão distribuídos nas dimensões ambientais, sociodemográfica e institucional.

\section{1) Dimensão ambiental}

a) Serviços de infraestrutura

Foram analisados os seguintes indicadores do IBGE: Acesso a sistema de abastecimento de água,Acesso a esgotamento sanitário,Acesso a serviço de coleta de lixo doméstico,Tratamento de esgoto e Destinação final do lixo. Como indicador do IPP, foi incluído neste grupo: Acesso à infraestrutura.

Enquanto o IBGE individualiza o acesso a cada serviço de infraestrutura (rede de água, coleta de esgoto e coleta de lixo), com a construção de indicadores que representam o percentual da população atendida por cada um desses sistemas, o IPP destaca um indicador síntese, que mostra a população com acesso a sistemas de abastecimento de água e de esgotamento sanitário, e a serviço de coleta de lixo, também em valores percentuais. Tanto o IBGE como o IPP utiliza como fonte de dados os resultados de coletas realizadas pelo primeiro órgão, como os censos demográficos a as Pesquisas Nacionais por Amostras de Domicílios (PNAD).

O acesso a este conjunto de serviços é um fator básico para o alcance de níveis de saúde desejados, por meio do controle e da redução de doenças - notadamente as de veiculação hídrica - e a manutenção da qualidade e da proteção ambiental, ou seja, indicadores consagrados de qualidade de vida e de desenvolvimento sustentável. Ao longo das últimas décadas tem crescido nas áreas urbanas os percentuais de coleta de lixo domiciliar e de população com abastecimento de água considerado adequado. Em menor escala, também avança no país a ligação de domicílios às redes de coleta de esgoto.

Além desses, o IBGE também inclui em seu estudo outros importantes indicadores: Tratamento de esgoto e Destinação final do lixo. Eles expressam, respectivamente, a capacidade de tratar o esgoto coletado e de ser dada uma destinação final adequada ao lixo coletado, considerando os percentuais em relação aos volumes

Geo UERJ - Ano 14, nº. 23, v. 2, $2^{\circ}$ semestre de 2012 p. 413-436

ISSN: 1415-7543 E-ISSN: 1981-9021

http://www.e-publicacoes.uerj.br/index.php/geouerj 
totais em questão. Como fontes de dados, aparecem o Sistema Nacional de Informações sobre Saneamento (SNIS), do Ministério das Cidades, e a Pesquisa Nacional de Saneamento Básico (PNSB), do IBGE.

Apenas coletar os esgotos domésticos é um serviço insuficiente no trato das questões ambientais; tratá-lo deve ser considerado como fundamental para a preservação da qualidade da água dos corpos hídricos que o recebem, e também para a proteção da população e das atividades que envolvem outros usos dessas águas. De maneira similar, além da coleta do lixo, o seu tratamento e a destinação adequada são condições essenciais para a preservação da qualidade ambiental e da saúde da população. Dessa forma, esses também são indicadores importantes para a caracterização básica da qualidade de vida da população e das atividades que fazem uso dos solos e das águas. Apesar de ser constatado um aumento substancial nos últimos anos, o total de esgoto coletado e tratado ainda está longe de atingir percentuais considerados satisfatórios; situação semelhante ocorre na quantidade de lixo que recebe destinação final adequada, sendo que, neste caso, o resultado é mais significativo, visto que os volumes totais de lixo coletado aumentaram na mesma proporção.

b) Uso do Solo

Foram incluídos sete indicadores, todos do IPP: Alteração de áreas naturais por áreas antrópicas; Variação da área de cobertura vegetal nativa; Crescimento da urbanização; Evolução da área urbana em encostas; Qualidade ambiental das terras; População nas unidades de conservação; e Proximidade de favelas às unidades de conservação.

As fontes de dados para a composição dos indicadores são da própria prefeitura (Secretaria Municipal de Meio Ambiente - Rio de Janeiro e IPP), além de órgãos da esfera federal, como a Embrapa e o IBGE.

Dois indicadores estão diretamente relacionados às áreas de vegetação nativa. A Alteração de áreas naturais por áreas antrópicas expressa a superfície na qual a ocupação urbana foi mais intensa, ou seja, onde houve a substituição de forma permanente das áreas de cobertura vegetal nativa por áreas urbanas ou degradadas. Por sua vez, a Variação da área de cobertura vegetal nativa indica a área da cobertura

Geo UERJ - Ano 14, nº. 23, v. 2, $2^{\circ}$ semestre de 2012 p. 413-436

ISSN: 1415-7543 E-ISSN: 1981-9021

http://www.e-publicacoes.uerj.br/index.php/geouerj 
vegetal nativa na superfície do município e suas tendências de variação em um período de tempo. É oportuno considerar a intensidade de perda permanente de áreas naturais como um fator básico para a formulação de propostas que visem à redução da velocidade desse processo e minimizem os impactos decorrentes, considerando que os diferentes tipos de cobertura vegetal desempenham importantes funções na manutenção das condições ambientais e na preservação da paisagem.

Os outros quatro indicadores analisados se direcionam ao processo de urbanização e as consequências daí decorrentes: Crescimento da urbanização; Evolução da área urbana em encostas; População nas unidades de conservação; e Qualidade ambiental das terras.

O indicador Crescimento da urbanização, de maior generalidade, mostra a intensidade de crescimento das áreas ocupadas pelo uso urbano, ao expressar, em unidades de área, as superfícies em que usos não urbanos foram convertidos para uso urbano.O monitoramento contínuo deste processo ao longo do tempo auxilia a análise da sua intensidade e a sua espacialização, possibilitando, ainda, a visualização da dinâmica de ocupação do solo na cidade. A urbanização implica perda, muitas vezes de forma irreversível, de vários recursos naturais existentes no espaço, dentre os quais cobertura florestal, mananciais e reservas de área agricultável.

Dentro desse contexto, a Evolução da área urbana em encostas é uma visão mais específica do indicador anterior. Ele identifica a intensidade com que as áreas de encostas, com cobertura vegetal e situadas acima da cota de 100 metros, foram convertidas para uso urbano no decorrer de um período. Considerando as características naturais da cidade e a forma desordenada como se deu essa ocupação, surgem como consequências negativas para o ambiente, por exemplo, os desmoronamentos, o assoreamento de rios e canais, o aumento de cheias nas áreas a jusante da ocupação; e perda da biodiversidade, entre outras.

Ainda no âmbito dos impactos negativos gerados a partir da ocupação urbana, é apresentado o indicador Qualidade ambiental das terras, que mostra o estado atual das terras, resultante da pressão antrópica sobre os atributos naturais do solo e de como o próprio ambiente reage a esta pressão. Foram consideradas a suscetibilidade à erosão, no caso das terras altas, e as restrições de drenagem, no caso das terras baixas.

Geo UERJ - Ano 14, no. 23, v. 2, $2^{\circ}$ semestre de 2012 p. 413-436

ISSN: 1415-7543 E-ISSN: 1981-9021

http://www.e-publicacoes.uerj.br/index.php/geouerj 
Admitindo-se que o solo é um fator natural de desenvolvimento e que ocupa uma importante posição nas atividades humanas, torna-se imprescindível ao planejamento minimizar o impacto das atividades urbanas neste recurso, bem como avaliar as necessidades de recuperação florestal.

Por fim, os outros dois indicadores analisados estão ligados às unidades de conservação: População nas unidades de conservação e Proximidade de Favelas às unidades de conservação. Enquanto o primeiro mostra a estimativa de população e a densidade demográfica no interior das unidades de conservação, a partir da identificação da área edificada, o segundo identifica a quantidade de favelas inseridas ou nas proximidades (até 100 metros) de unidades de conservação localizadas no município. Em ambos os casos, como forma de ampliar a representatividade, os indicadores podem vir acompanhados de mapas que apontem como a população se distribui nestes espaços. Assim, conhecendo o nível de pressão da ocupação humana nas unidades de conservação e a expressão do avanço dos assentamentos informais pelas encostas e nas margens dos rios, há a contribuição para os processos de gestão dos territórios protegidos por lei.

\section{2) Dimensão sociodemográfica}

Os indicadores incluídos na dimensão sociodemográfica procuram descrever características e processos relacionados à população: Taxa de crescimento da população (IBGE), Taxa de crescimento populacional (IPP), Densidade demográfica (IPP), e Percentual da população em assentamentos informais - favelas (IPP); e às moradias: Densidade domiciliar (IPP), Inadequação de moradia (IPP), e Adequação de moradia (IBGE); e à saúde: Oferta de serviços básicos de saúde (IBGE) e Doenças relacionadas ao saneamento ambiental inadequado (IPP).

Numa visão geral, já pode ser percebida a similaridade entre determinados indicadores dos referidos órgãos, que descrevem situações e comportamentos idênticos ou complementares, inclusive com as mesmas fontes de dados.

Os indicadores Taxa de crescimento da população e Taxa de crescimento populacional são exemplos dessa situação, ao descreverem da mesma forma e com os

Geo UERJ - Ano 14, nº. 23, v. 2, $2^{\circ}$ semestre de 2012 p. 413-436

ISSN: 1415-7543 E-ISSN: 1981-9021

http://www.e-publicacoes.uerj.br/index.php/geouerj 
mesmos dados dos Censos Demográficos do IBGE, o ritmo de crescimento populacional anual para cada década, em determinada área. Esse indicador é fundamental para subsidiar a formulação de políticas publicas de naturezas social, econômica e ambiental, uma vez que permite o dimensionamento de demandas, tais como o acesso a serviços e equipamentos básicos de saúde e de saneamento, educação, infraestrutura social, emprego, entre outras. Quando integrado a Sistemas de Informações Geográficas, o poder desse indicador se amplifica, pois a localização dessas ações também é possível.

O indicador Densidade demográfica, que também se apoia em dados dos Censos demográficos do IBGE, objetiva expressar o número médio de pessoas em um determinado território, o que é uma importante referência para avaliar a distribuição das áreas urbanas, da infraestrutura e dos serviços públicos e, consequentemente, dos impactos no meio natural e na qualidade de vida.

Ainda em relação à população, o indicador Percentual da população em assentamentos informais - favelas aponta o percentual de população em setores censitários classificados como aglomerados subnormais, de acordo com os dados dos Censos demográficos do IBGE. Ao estimar o tamanho da informalidade habitacional da cidade, o indicador expressa a dificuldade de acesso à terra urbana para fins habitacionais e também a fragmentação da cidade ocasionada pela segregação social. A sua importância é igualmente relevante ao abordar, mesmo que de forma indireta, as questões ligadas à insegurança dos moradores no que concerne à sua permanência na área, tanto pela fragilidade ambiental, como pelos impactos na saúde da população.

O grupo de indicadores que estão ligados às moradias utiliza como fonte de dados os Censos demográficos do IBGE e as PNAD. A Densidade domiciliar indica o número médio de moradores por domicílio em uma região e é um indicador universal de avaliação das condições de habitação nos centros urbanos. A Adequação de moradia e a Inadequação de moradia são um exemplo de complementaridade entre indicadores, ao sintetizarem as características das moradias e apontarem aquelas que possuem (ou não) condições mínimas de habitabilidade. Entre os itens essenciais a serem tratados no desenvolvimento sustentável, destaca-se a habitação. A moradia adequada pode contribuir para a qualidade ambiental, quando o esgoto e o lixo são coletados e Geo UERJ - Ano 14, no. 23, v. 2, $2^{\circ}$ semestre de 2012 p. 413-436

ISSN: 1415-7543 E-ISSN: 1981-9021

http://www.e-publicacoes.uerj.br/index.php/geouerj 
adequadamente dispostos, evitando a proliferação de vetores de doenças. Dessa forma, um domicílio adequado é uma das condições determinantes para a qualidade de vida da população.

Foi definido como condição inadequada de habitabilidade: o "adensamento excessivo" (mais de três moradores por dormitório); a "carência de serviços de infraestrutura" (sem acesso a pelo menos um dos serviços: a rede geral de água, a rede de esgotamento sanitário ou fossa séptica, a coleta de lixo - direta ou indireta); a inexistência de unidade sanitária de uso exclusivo; e a inexistência de serviço de iluminação elétrica.

Dois indicadores retratam as condições de saúde: Oferta de serviços básicos de saúde e Doenças relacionadas ao saneamento ambiental inadequado, apoiados em dados do IBGE e da Secretaria Municipal de Saúde - Rio de Janeiro.

O primeiro indicador expressa a disponibilidade, na área de saúde, de recursos humanos e equipamentos físicos para a população residente, considerando a razão entre a população residente e o número de estabelecimentos de saúde; de postos de trabalho médico; e de leitos hospitalares. O acesso universal aos serviços de saúde é condição para a conquista e manutenção da qualidade de vida. Este indicador é relevante por expressar a o potencial de acesso aos mesmos por parte da população.

O segundo indicador aponta o risco de adoecer ou morrer, e a gravidade do problema causado pela ocorrência das doenças e agravos relacionados a deficiências do sistema de saneamento ambiental, como a dengue, a leptospirose, a leishmaniose e a hepatite A. Os investimentos em saneamento são considerados como redutores dos custos com saúde e a sua priorização e o seu direcionamento de recursos são normalmente baseados nas taxas de incidência, mortalidade e letalidade.

\section{3) Dimensão institucional}

A dimensão institucional agrega as ações de iniciativa governamental, como aquelas referentes a atuações de seus órgãos, e também de organismos da sociedade civil, inclusive aos que apresentam a participação de diferentes níveis de governo.

No que tange às ações de responsabilidade governamental estão os indicadores denominados Reflorestamento com espécies nativas; Áreas protegidas como unidades

Geo UERJ - Ano 14, nº. 23, v. 2, $2^{\circ}$ semestre de 2012 p. 413-436

ISSN: 1415-7543 E-ISSN: 1981-9021

http://www.e-publicacoes.uerj.br/index.php/geouerj 
de conservação; Fiscalização ambiental; e Atendimentos da defesa civil relacionados ao meio ambiente. Todos esses indicadores foram elaborados pelo IPP, com as fontes de dados da Secretaria Municipal de Meio Ambiente e da Defesa Civil do Município do Rio de Janeiro.

O Reflorestamento com espécies nativas refere-se à evolução da área territorial implantada de reflorestamento, consideradas apenas as iniciativas do poder público. Enquanto, por um lado, ocorre a perda gradativa de cobertura florestal, substituída para uso urbano ou consumida e transformada em área degradada, surge, na direção oposta, a demanda de atuação da prefeitura, no sentido de recuperação da vegetação nativa.

O indicador Áreas protegidas como unidades de conservação mostra a extensão dos espaços territoriais protegidos pelas tutelas federal, estadual e municipal na cidade do Rio de Janeiro, de acordo com o Sistema Nacional de Unidades de Conservação (SNUC). Assim, há a avaliação da presença e da evolução desse instrumento de gestão urbana e ambiental, identificando quantidade e concentração das áreas protegidas na cidade. $\mathrm{O}$ indicador também auxilia na avaliação dos benefícios ambientais oriundos da criação e manutenção de áreas protegidas. Dentre estes benefícios, destacam-se: preservação da biodiversidade, manutenção de um estoque de terras permeáveis e a disponibilização de áreas livres para recreação e lazer.

A Fiscalização ambiental identifica as vistorias realizadas pela atividade de fiscalização ambiental da Administração Municipal e é um indicador que demonstra o alcance e a magnitude da atividade de fiscalização ambiental. O grau de preservação dos recursos naturais e as possibilidades de regeneração do ambiente estão intimamente relacionados à eficácia dos mecanismos de controle do poder público.

Por fim, os Atendimentos da defesa civil relacionados ao meio ambiente expressam a evolução do número de registros de atendimento pela Defesa Civil Municipal, em casos de dano ou acidente ambiental. O acompanhamento da frequência desses eventos pode demonstrar o grau de fragilidade da cidade em relação a diversos e prováveis riscos de acidentes. Pode, assim, constituir subsídio para formulação de propostas de controle das atividades causadoras do risco e consequentemente a redução de danos e de despesas. Com o indicador, podem-se detectar duas categorias de acidentes relacionados ao meio ambiente: os que são provocados por alterações das

Geo UERJ - Ano 14, no. 23, v. 2, $2^{\circ}$ semestre de 2012 p. 413-436

ISSN: 1415-7543 E-ISSN: 1981-9021

http://www.e-publicacoes.uerj.br/index.php/geouerj 
condições do meio físico, tais como deslizamentos e inundações, e os que são consequências de atividades impactantes ou potencialmente poluidoras, como explosões, contaminações, dentre outros.

Ainda inseridos na dimensão institucional, estão os indicadores Conselhos Municipais de Meio Ambiente; Comitês de Bacias Hidrográficas; Organizações da sociedade civil; e Agenda 21 Local, todos elaborados pelo IBGE e contando com a sua base de dados.

Os dois primeiros indicadores medem a proporção de municípios que, respectivamente, estão dotados de Conselhos Municipais de Meio Ambiente, e que participam de Comitês de Bacias Hidrográficas, em relação ao número total de municípios das Unidades da Federação e do país. A existência de conselhos de meio ambiente ativos revela o nível de organização municipal no que se refere à democratização da gestão de políticas publicas e reflete o interesse da municipalidade nas especificidades locais. Assim, a gestão do meio ambiente, na esfera municipal, pode contribuir para a melhoria da qualidade de vida da população. Já os comitês de bacias representam uma forma de articulação intermunicipal ou entre a União e os estados. Trata-se, portanto, de um modelo de gestão descentralizado e participativo para a tomada de decisões relativas ao uso, à recuperação, e a conservação dos recursos hídricos - recursos estes que tem um papel importante para a saúde pública, entre outros objetivos de desenvolvimento sustentável.

O indicador Organizações da sociedade civil apresenta o número de fundações privadas e associações sem fins lucrativos em uma determinada população. As organizações da sociedade civil possuem diversas finalidades, que, em seu conjunto, contribuem para aumentar a capacidade da sociedade de exercer a sua cidadania e desenvolver-se de forma sustentável; representam, portanto, a capacidade de organização da sociedade civil e de intervenção ativa das comunidades na realidade em que vivem.

Concluindo, há o indicador Agenda 21 Local, que expressa a disseminação desse documento, apontando a proporção da população residente em municípios com alguma de suas etapas concluída, em relação à população total residente segundo as unidades territoriais consideradas. Este indicador revela a magnitude que as iniciativas de

Geo UERJ - Ano 14, nº. 23, v. 2, $2^{\circ}$ semestre de 2012 p. 413-436

ISSN: 1415-7543 E-ISSN: 1981-9021

http://www.e-publicacoes.uerj.br/index.php/geouerj 
implementação da Agenda 21 alcançaram no Brasil, além de mostrar o quanto a sociedade, as empresas e os governos se mobilizaram para a efetivação de tais ações nos anos seguintes a Rio 92.

\section{LIMITAÇÕES E POTENCIALIDADES NA APLICAÇÃO DE INDICADORES EM ÂMBITO LOCAL}

A aplicação de indicadores para distintos recortes esbarra em um problema recorrente, o da obtenção de dados. A partir desta visão, deve-se atentar às dificuldades no contexto brasileiro com relação à existência, disponibilidade e confiabilidade dos dados, necessários à construção de indicadores e efetiva visualização dos fenômenos avaliados. Ou seja, a aplicação de um indicador pode ser impedida pela inexistência do dado. Quando existente, o mesmo nem sempre está disponível, e, quando disponível, nem sempre é confiável.

As dificuldades mais expressivas se relacionam ainda com a temporalidade dos dados. As séries temporais são recentes, e seus intervalos ainda grandes. Os dados demográficos advindos do censo, por exemplo, constituem informações confiáveis, porém limitadas pelo intervalo de dez anos para o seu levantamento, o que é uma faixa viável dada a coleta por todo o território nacional. Atenta-se ainda ao fato de que os dados podem ser disponibilizados temporalmente, mas não para o recorte espacial pretendido. É comum a existência de dados relativos a séries temporais para unidades territoriais (políticas e administrativas) mais extensas.

Em contrapartida aos dados quantitativos, observa-se uma lacuna quanto ao levantamento de dados qualitativos diretamente relacionados às análises ambientais. A periodicidade dos dados é prejudicada pelas dificuldades metodológicas e o custo de seu levantamento. Isto é latente em órgãos vinculados às prefeituras municipais, que, em muitas vezes, não possuem recursos tecnológicos e humanos para o levantamento de dados de forma padronizada.

A integração de indicadores sociais e ambientais, além do resultado de sua análise, tornam-se medidas promissoras para uma efetiva interpretação da realidade, ao rever processos interativos que envolvem natureza e sociedade.

Geo UERJ - Ano 14, nº. 23, v. 2, $2^{\circ}$ semestre de 2012 p. 413-436

ISSN: 1415-7543 E-ISSN: 1981-9021

http://www.e-publicacoes.uerj.br/index.php/geouerj 
A complexidade da tomada de decisão requer um tratamento qualificado e justifica a utilização de métodos de apoio à mesma. A modelagem do mundo real em um Sistema de Informações Geográficas - $\mathrm{SIG}^{2}$, frente ao estabelecimento de um grupo de indicadores, pode atender às múltiplas demandas socioambientais e a necessidade de intervir na realidade. A espacialização dos dados, para a construção de indicadores com expressão espacial, é de extrema importância em análises ambientais, pois identificam a localização dos objetos e seus relacionamentos.

Porém, há uma grande dificuldade no tratamento de dados com expressão espacial, ainda maior do que a dos dados convencionais, ou tabulares. O levantamento de dados espaciais exige uma confiabilidade técnica ainda maior, pois o dado passa a possuir localização exata na superfície terrestre.

Deve ser ainda revista a disponibilidade de dados espaciais com resolução/escala compatível com o objeto estudado. Devem ser consultados a existência e o acesso a fontes primárias (ortofotos ou imagens de alta resolução, ainda de custo elevado para prefeituras) e secundárias (mapeamentos pré-existentes). É comum se deparar com a existência de dados espaciais em escalas compatíveis com o nível regionais, não condizentes com a visualização de objetos de expressão local.

A mensuração de indicadores em escala local demanda por parte de prefeituras e órgãos públicos um conjunto de investimentos, principalmente no tocante à obtenção de dados com rigor metodológico que garanta a sua qualidade e efetiva representatividade. Para isto, torna-se imprescindível a capacitação teórico-metodológica de recursos humanos e a disponibilidade técnica e tecnológica para o levantamento, o processamento e a interpretação de dados.

No atual momento de incessantes conquistas no campo informacional, a pesquisa científica deve-se valer desses avanços tecnológicos nas etapas de mensuração de dados para a elaboração de indicadores. Entre essas ferramentas, a serem incorporadas e utilizadas por esses recursos humanos capacitados, está a internet, os aparelhos de GPS, os tablets, o armazenamento em nuvem, entre outras.

\section{CONSIDERAÇÕES FINAIS}

Geo UERJ - Ano 14, nº. 23, v. 2, $2^{\circ}$ semestre de 2012 p. 413-436

ISSN: 1415-7543 E-ISSN: 1981-9021

http://www.e-publicacoes.uerj.br/index.php/geouerj 
Mais do que a simples utilização de indicadores de maneira isolada, a integração destes parece ser um caminho para alcançar a descrição de uma realidade complexa, operada por diversos processos de diferentes dimensões. É nesse contexto de complexidade, onde há a atuação de múltiplos atores e a ocorrência de variados fenômenos, que emergem riscos e vulnerabilidades, as quais atingem ambientes e grupos sociais em escalas distintas e relacionadas.

Tratar de riscos demanda o diagnóstico da realidade, sobretudo em escala local. Atentando para as suas limitações e potencialidades, os indicadores podem se constituir em elementos que conduzam a esse propósito.

No caso da PNPDEC, que se configura uma ação política para a gestão de riscos de desastres no Brasil, a aplicação dos indicadores das três dimensões propostas (ambiental, sociodemográfica e institucional) podem subsidiar os atores envolvidos em câmaras técnicas e temáticas, associadas às diferentes realidades territoriais, na composição dos planos diretores dos municípios que farão parte do cadastro nacional, atendendo aos anseios da política.

Os indicadores ambientais como um todo pode ser direcionado a composição de um diagnóstico que objetive a identificação e o mapeamento de áreas de risco, a partir do cruzamento de diferentes planos de informação, que contemplem as relações sociedade e natureza e as suas expressões na paisagem.

Além de os indicadores ambientais contribuírem para o planejamento no âmbito da política, outra participação potencialmente relevante se configura no contexto do direcionamento de ações corretivas a partir da identificação e definição de áreas prioritárias, integradas ao Sistema Nacional de Proteção e Defesa Civil - SINPDEC.

A aplicação dos indicadores sociodemográficos atende ao diagnóstico socioambiental, o qual deve ampliar o reconhecimento de vulnerabilidades, como a identificação de grupos com diferentes níveis de exposição aos riscos, e o planejamento de ações prioritárias no âmbito da referida política.

Por fim, os indicadores institucionais podem auxiliarna avaliação quanto ao nível de organização dos atores envolvidos na implementação da PNPDEC e de suas ações práticas realizadas, revelando ainda estruturas pré-existentes. Podem contribuir

Geo UERJ - Ano 14, nº. 23, v. 2, $2^{\circ}$ semestre de 2012 p. 413-436

ISSN: 1415-7543 E-ISSN: 1981-9021

http://www.e-publicacoes.uerj.br/index.php/geouerj 
também ao diagnóstico da realidade por meio da identificação de outras respostas, associadas ao tema, e suas implicações com relação às transformações do território.

\section{NOTAS}

1 - O Estatuto da Cidade definiu que além das cidades com mais de vinte mil habitantes o Plano Diretor também é obrigatório para cidades: integrantes de regiões metropolitanas e aglomerações urbanas; com áreas de especial interesse turístico; situados em áreas de influência de empreendimentos ou atividades com significativo impacto ambiental na região ou no país. (BRASIL, 2001).

2 -Os Sistemas de Informação Geográfica permitem realizar análises e integrar dados a partir da criação de bancos de dados espaciais. O conceito de SIG está vinculado à capacidade de extração da informação geográfica e ganho de conhecimento, a partir da análise espacial (CONCEIÇÃO e COSTA, 2011).

\section{BIBLIOGRAFIA}

BATATA, A. G. R. Indicadores de viabilidade econômica-geográfica, ambiental e sócio-política para a implementação de Programa de coleta seletiva. Porto Alegre: UFRGS, 2004. 296 p. Dissertação (Mestrado em Planejamento Urbano e Regional) Arquitetura e Urbanismo, Universidade Federal do Rio Grande do Sul, Porto Alegre, 2004.

BELLEN, H. M. V. Indicadores de Sustentabilidade: Uma Análise Comparativa. Rio de Janeiro: ed. FGV, 2007. 253 p.

BOLLMANN, H. A. Avaliação ambiental integrada. In: V Seminário Fluminense de Indicadores, Rio de Janeiro. Caderno de textos. Rio de Janeiro: CEPERJ, 2009.

BRASIL. 2001.Estatuto da Cidade: Guia para implementação pelos municípios e cidadãos. Brasília: Câmara dos Deputados, Coordenação de Publicações, 2001. 2012. Lei $\mathbf{n}^{\mathbf{0}}$ 12.608, de 10 de Abril de 2012. Institui a Política Nacional de Proteção e Defesa Civil - PNPDEC. Disponível em: <http://www.planalto.gov.br/ccivil_03/_Ato2011-2014/2012/Lei/L12608.htm>. Acesso em: 14 abr. 2012.

BREDARIOL, C.; VIEIRA, L. Cidadania e Política Ambiental. Rio de Janeiro - São Paulo: Editora Record, 1998. 171 p.

Geo UERJ - Ano 14, nº. 23, v. 2, $2^{\circ}$ semestre de 2012 p. 413-436

ISSN: 1415-7543 E-ISSN: 1981-9021

http://www.e-publicacoes.uerj.br/index.php/geouerj 
CONCEIÇÃO, R. S.; COSTA, V. C. Cartografia e Geoprocessamento. v. 2. Rio de Janeiro: Fundação CECIERJ, 2011. 255 p.

CONSÓRCIO PARCERIA 21. Metodologia para elaboração de Informes GEO

Cidades: manual de aplicação. Rio de Janeiro: Instituto Brasileirode Administração Municipal - IBAM/Instituto de Estudos da Religião - ISER/ Rede deDesenvolvimento Humano - REDEH, 2002.

DEUS, A. B. S. Gerenciamento de serviços de limpeza urbana: Avaliação por indicadores e índices. Porto Alegre: UFRGS, 2000. 181 p. Tese (Doutorado em Engenharia) - Engenharia de Recursos Hídricos e Saneamento Ambiental, Universidade Federal do Rio Grande do Sul, Porto Alegre, 2000.

GARCIAS, C. M. Indicadores de qualidade dos serviços e infraestrutura urbana de saneamento. São Paulo: USP, 1991. 206 p. Tese (Doutorado em Engenharia Civil) Escola Politécnica, Universidade de São Paulo, São Paulo, 1991.

IBGE - Instituto Brasileiro de Geografia e Estatística. Indicadores de Desenvolvimento Sustentável. Instituto Brasileiro de Geografia e Estatística, Coordenação de Recursos Naturais e Estudos Ambientais. Coordenação de Geografia. Rio de Janeiro: IBGE, 2012. 350 p.

IPP - Instituto Pereira Passos. Indicadores Ambientais da Cidade do Rio de Janeiro. Rio de Janeiro: Urbanismo / Pereira Passos, 2005. 178 p.

JANNUZZI, P. M. Indicadores Sociais no Brasil. Campinas: Editora Alínea, 2001. $141 \mathrm{p}$.

MIBIELLI, P. G. A construção de indicadores ambientais para gestão municipal Experiência da pesquisa de informações básicas municipais do IBGE. In: V Seminário Fluminense de Indicadores, Rio de Janeiro. Caderno de textos. Rio de Janeiro: CEPERJ, 2009.

SOUZA, M. L. Mudar a cidade: Uma introdução crítica ao planejamento e à gestão urbanos. Rio de Janeiro: Bertrand Brasil, 2002. 556p.

Artigo encaminhado para publicação em outubro de 2012.

Artigo aceito para publicação em novembro de 2012.

Geo UERJ - Ano 14, $\mathrm{n}^{\circ} .23$, v. 2, $2^{\circ}$ semestre de 2012 p. 413-436

ISSN: 1415-7543 E-ISSN: 1981-9021

http://www.e-publicacoes.uerj.br/index.php/geouerj 